\title{
EDITORIAL
}

\section{Journal of Infrastructure, Policy and Development has been indexed by Emerging Sources Citation Index-An important step forward}

Amidst the protracted COVID-19 crisis, we need more encouraging news. I am now sharing a morale-boosting outcome: the Journal of Infrastructure, Policy and Development (JIPD) was recently selected for inclusion in the Web of Science Core Collection. All articles published in JIPD since its inaugural will be indexed in the Emerging Sources Citation Index (ESCI), which means authors publishing in JIPD will enjoy maximum exposure of their research.

This accomplishment signifies a critical milestone for JIPD. While celebrating our inclusion in ESCI, I would like to take this opportunity to thank all members of the Advisory Board, particularly Professor Justin Yifu Lin, the Dean of Institute of New Structural Economics at Peking University and the former Senior Vice President and Chief Economist of the World Bank, for all of his guidance in getting us to this point.

I would also like to extend my deepest gratitude to the Editorial Board for their tremendous contribution to the journal on the path towards this achievement. Of course, we wouldn't be anywhere today without all of the excellent work submitted by JIPD authors, as well as the passion and critical comments by our devoted reviewers.

Special thanks go to Professor Giuseppe Eusepi, our associate editor, who consistently inspired us to strive for a high-quality journal. Unfortunately, Giuseppe passed away in last October.

Infrastructure plays a vital role in sustained, broadly shared economic growth and alleviation of poverty. The world has recently witnessed that infrastructure contributes significantly to the economic recovery amid the COVID-19. Our journal is dedicated to providing a reliable platform to encourage discussions and analyses of infrastructure development issues, and further promote dialogue in this area. A novelty of this journal is that it covers the whole range of infrastructure, hence including both "hard" infrastructure and "soft" infrastructure. In addition, it discusses how the institutional infrastructure may be applied to different physical infrastructure activities, with the support of effective government policy, to reach the ultimate aim of development.

We will continue to move the journal forward and strive towards indexing in Science Citation Index Expanded (SCIE) / Social Sciences Citation Index (SSCI) in the near future. Let us work together to move the journal forward in ways that promote high-quality research and advocate for a solid understanding of infrastructure development.

Editor-in-Chief

Qingyang $\mathrm{Gu}$ 